\title{
Sentimentos e mudanças na vida dos acadêmicos da saúde frente à COVID-19
}

\author{
Feelings and changes in the life of health academies in front of COVID-19
}

Sentimientos y cambios en la vida de los académicos de la salud frente al COVID-19

Recebido: 25/07/2021 | Revisado: 30/07/2021 | Aceito: 02/08/2021 | Publicado: 07/08/2021

\author{
Graciela Soares Fonseca \\ ORCID: https://orcid.org/ 0000-0001-9506-0409 \\ Universidade Federal da Fronteira Sul, Brasil \\ E-mail: graciela.fpnseca@uffs.edu.br \\ Jeane Barros de Souza \\ ORCID: https://orcid.org/ 0000-0002-0512-9765 \\ Universidade Federal da Fronteira Sul, Brasil \\ E-mail: jeane.souza@uffs.edu.br \\ Vander Monteiro da Conceição \\ ORCID: https://orcid.org/ 0000-0003-0972-0795 \\ Universidade Federal da Fronteira Sul, Brasil \\ E-mail: vander.conceicao@uffs.edu.br \\ Crhis Netto de Brum \\ ORCID: https://orcid.org/ 0000-0002-2970-1906 \\ Universidade Federal da Fronteira Sul, Brasil \\ E-mail: crhis.brum@uffs.edu.br \\ Eleine Maestri \\ ORCID: https://orcid.org/ 0000-0002-0409-5102 \\ Universidade Federal da Fronteira Sul, Brasil \\ E-mail: eleine.maestri@uffs.edu.br \\ Jeferson Santos Araújo \\ ORCID: https://orcid.org/ 0000-0003-3311-8446 \\ Universidade Federal da Fronteira Sul, Brasil \\ E-mail: jeferson.araujo@uffs.edu.br
}

\section{Resumo}

O artigo objetiva compreender as repercussões da pandemia de COVID-19 para a vida dos estudantes de graduação da área da saúde. Trata-se de estudo qualitativo, do tipo ação participante, fundamentado nos pressupostos teórico metodológicos de Paulo Freire. Percorreu-se o Itinerário de Pesquisa de Freire, que possui três etapas interligadas: Investigação Temática; Codificação e Descodificação; e o Desvelamento Crítico. Foi realizado um Círculo de Cultura virtual com a participação de 15 estudantes de diferentes universidades de Santa Catarina, Brasil, em julho de 2020. Os estudantes destacaram que frente a pandemia desenvolveram sentimentos de incertezas, iminência da morte, insegurança, angústia, desânimo, frustração, desconforto, ansiedade, raiva, preocupações, medo, impotência e várias dúvidas sobre a qualidade da sua formação. Apontaram que durante o momento de pandemia faz-se necessário resinificar prioridades pessoais e acadêmicas por meios de momentos que promovam a autorreflexão, autoconhecimento, empatia, amor, resiliência e o protagonismo. A investigação proporcionou conhecer os sentimentos que permeiam o imaginário dos estudantes de cursos de graduação em saúde e desvelar as transformações impostas pela pandemia, ampliando a compreensão relacionada às ressignificações e modos de viver encontrados por eles. O Círculo de Cultura virtual foi interpretado como um dispositivo terapêutico e um recurso de pesquisa adequado para utilização em contextos onde o distanciamento social é imperativo.

Palavras-chave: Ensino; Estudantes de ciências da saúde; COVID-19; Pandemias; Incerteza.

\begin{abstract}
The aims to understand the repercussions of the COVID-19 pandemic on the lives of undergraduate health students. It's a qualitative study, of the participant action type, based on Paulo Freire's theoretical methodological assumptions. Freire's Research Itinerary was visited, which has three interconnected stages: Thematic Research; Encoding and Decoding; and Critical Unveiling. A virtual Culture Circle was held with the participation of 15 students from different universities in Santa Catarina, Brazil, in July 2020. The students highlighted that in the face of the pandemic they developed feelings of uncertainty, imminence of death, insecurity, anguish, discouragement, frustration, discomfort, anxiety, anger, concerns, fear, impotence and several doubts about the quality of their training. They pointed out that during the pandemic, it is necessary to reshape personal and academic priorities by means of moments that promote self-reflection, self-knowledge, empathy, love, resilience and protagonism. The investigation provided knowledge of the feelings that permeate the imagination of students of undergraduate health courses and unveil the transformations imposed by the pandemic, expanding the understanding related to the resignifications and ways of life
\end{abstract}


found by them. The Virtual Culture Circle was interpreted as a therapeutic device and a research resource suitable for use in contexts where social distance is imperative.

Keywords: Teaching; Health science students; COVID-19; Pandemics; Uncertainty.

\section{Resumem}

El artículo tiene como objetivo comprender las repercusiones de la pandemia COVID-19 en la vida de los estudiantes de pregrado en el área de la salud. Se trata de un estudio cualitativo, del tipo acción participante, basado en los supuestos teóricos y metodológicos de Paulo Freire. Se siguió el Itinerario de Investigación Freire, que tiene tres etapas interconectadas: Investigación Temática; Codificación y decodificación; y la Revelación Crítica. Se realizó un Círculo de Cultura virtual con la participación de 15 estudiantes de diferentes universidades de Santa Catarina, Brasil, en julio de 2020. Los estudiantes destacaron que, ante la pandemia, desarrollaron sentimientos de incertidumbre, muerte inminente, inseguridad, angustia, desánimo, frustración, malestar, ansiedad, enfado, preocupaciones, miedo, impotencia y diversas dudas sobre la calidad de su formación. Señalaron que durante el momento de la pandemia es necesario volver a terminar las prioridades personales y académicas a través de momentos que promuevan la autorreflexión, el autoconocimiento, la empatía, el amor, la resiliencia y el protagonismo. La investigación permitió conocer los sentimientos que impregnan el imaginario de los estudiantes de licenciatura en salud y develar las transformaciones impuestas por la pandemia, ampliando el entendimiento relacionado con las resignificaciones y formas de vida encontradas por ellos. El Círculo Cultural virtual se interpretó como un dispositivo terapéutico y un recurso de investigación apto para su uso en contextos donde el distanciamiento social es imperativo.

Palabras clave: Enseñanza; Estudiantes del Área de la Salud; COVID-19; Pandemias; Incertidumbre.

\section{Introdução}

A Coronavirus Disease 2019 (COVID-19) foi identificada na província de Hubei, na China, em dezembro de 2019. Diante do registro da disseminação e aumento no número de casos da doença, ela foi classificada como uma pandemia, em março de 2020, gerando consequências para a saúde das pessoas (Wang et al., 2020) e impondo desafios sociais e econômicos (Singhal, 2020).

A COVID-19 causa infecções respiratórias em seres humanos, variando sua intensidade em cada indivíduo, geralmente em função das comorbidades que as pessoas apresentam, podendo se manifestar de forma severa e com alto índice de letalidade (Lipsitch et al., 2020; Silva et al., 2021). O vírus apresenta grau elevado de transmissibilidade e a infecção é adquirida por meio de gotículas ou por contato das mãos em superfícies contaminadas.

No Brasil, o primeiro caso de COVID-19 foi notificado no final de fevereiro de 2020 e em março, o primeiro óbito foi registrado. Em julho de 2021, o país registrou mais de 540.000 óbitos em decorrência da doença, reforçando o potencial devastador da COVID-19.

Como não há medicamentos específicos para o controle e as vacinas ainda não foi aplicada em toda a população, a prevenção torna-se essencial e ela acontece por meio da higienização frequente das mãos, do uso de máscaras, da etiqueta respiratória e do distanciamento social (Singhal, 2020).

Nesse contexto, as instituições de ensino superior tiveram suas atividades presenciais suspensas ao longo do ano de 2020, em vários países, a fim de conter o avanço da pandemia. No Brasil, muitas estão, até o momento, com as atividades suspensas.

O distanciamento social compulsório ocasionou transformações repentinas nos hábitos de vida. Especificamente no que se refere aos estudantes universitários, eles tiveram suas rotinas modificadas, com interrupção dos relacionamentos interpessoais oportunizados pela convivência acadêmica, a inclusão de novos modos de aprender em função do ensino remoto emergencial, a suspensão de estágios e atividades práticas, dentre outras modificações (Cao et al., 2020; Liu et al., 2020; Meo et al., 2020). Esse contexto, tende a exacerbar sentimentos como medo, tristeza, ansiedade e incertezas em relação ao futuro (Maia \& Dias, 2020), além de raiva, frustração, tédio e confusão (Aristovnik et al., 2020).

Estudos desenvolvidos com estudantes universitários de países diversos como China, Itália e Espanha, com o intuito de analisar os efeitos do lockdow instituído por esses países, reforçam os efeitos negativos da pandemia para a saúde mental 
desse grupo. Foram identificados o aumento de sintomas relacionados à ansiedade, à distúrbios alimentares, bem como o incremento no número de pessoas acometidas por transtornos mentais ou sofrimento psíquico (Marques et al., 2021).

Apesar de existir, na literatura científica, um número expressivo de trabalhos que abordam os efeitos da pandemia de COVID-19 para a saúde mental dos estudantes universitários, ainda são poucos os estudos que discutem outras repercussões desse momento atípico para esse grupo, como os sentimentos e transformações experienciadas, sobretudo utilizando abordagens qualitativas, o que justifica a realização do presente estudo.

Esse contexto revela a necessidade de conhecer os significados das vivências no período pandêmico, bem como as repercussões geradas por ele, para a vida dos estudantes de graduação, especialmente os da área da saúde, no sentido de revelar subsídios que possam contribuir para tornar esse processo menos danoso, a curto e a longo prazo, e enaltecer possíveis benefícios vistos a partir da ótica dos estudantes.

Assim, emergiu a seguinte questão de pesquisa: quais as repercussões da pandemia de COVID-19 para a vida dos estudantes de graduação da área da saúde? Logo, o estudo teve como objetivo compreender as repercussões da pandemia de COVID-19 para a vida dos estudantes de graduação da área da saúde.

\section{Metodologia}

Trata-se de uma pesquisa qualitativa, do tipo ação-participante, fundamentada no referencial teórico metodológico de Paulo Freire. O Itinerário de Pesquisa Freireano possui três etapas dialéticas, que estão interligadas entre si: 1) Investigação Temática: é o diálogo inicial em que se identifica os temas geradores que emergem da realidade dos participantes; 2) Codificação e Descodificação: reflexão dos temas geradores com representação crítica das situações existenciais sobre a realidade vivida; 3) Desvelamento Crítico: é a consciência crítica da situação existencial, em que se evidenciam os limites e as possibilidades da realidade (Heidemann et al., 2017).

O Itinerário de Pesquisa é desenvolvido no espaço denominado de Círculo de Cultura, que é conduzido por um mediador de maneira dialógica, horizontal e participativa, promovendo a reflexão e construção do saber oportunizado pelo compartilhamento de experiências e vivências, em que todos os envolvidos se transformam (Heidemann et al., 2017).

Participaram do estudo 15 estudantes da área da saúde, matriculados nas seguintes instituições de Santa Catarina, Brasil: Universidade Federal da Fronteira Sul (UFFS), Universidade do Estado de Santa Catarina (UDESC) e a Universidade do Oeste de Santa Catarina (UNOESC). Considerou-se critérios de inclusão ser estudante universitário de graduação de um curso da área da saúde de uma das universidades supracitadas e integrar o Programa de Educação pelo Trabalho para a Saúde (PET-Saúde) Interprofissionalidade. Como critérios de exclusão adotou-se: ter menos de 18 anos de idade, estar com a matrícula trancada no período e não ter acesso a dispositivos eletrônicos (computador ou celular) e acesso à internet para integrar o Círculo de Cultura.

Diante do momento pandêmico, o Círculo de Cultura foi realizado virtualmente, com o apoio de dispositivos eletrônicos. Utilizou-se a plataforma Google Meet, o que viabilizou a interação dos participantes do estudo, mesmo distantes fisicamente. Com o apoio dos coordenadores do PET-Saúde Interprossionalidade das instituições referidas, os pesquisadores obtiveram o contato dos estudantes. A partir de então, os estudantes foram convidados para participar da pesquisa, via mensagem no WhatsApp ${ }^{\circledast}$. Salienta-se que todos os estudantes contactados aceitaram participar do estudo, não havendo recusas ou exclusões. Optou-se pelo número de 15 participantes pelo fato de tratar-se de uma abordagem cuja natureza não deve possuir uma composição de um grupo maior de pessoas, a fim de possibilitar efetiva participação e discussão (Heidemann et al., 2017). 
Para percorrer o Itinerário de Pesquisa de Paulo Freire com ludicidade e interatividade, foi realizado uma analogia com o ciclo de vida da borboleta, possibilitando refletir e atravessar todas as etapas do Itinerário em um único encontro, conforme ilustração da Figura 1.

Figura 1 - Itinerário de pesquisa de Paulo Freire: vida das borboletas. Chapecó, SC, Brasil, 2020.

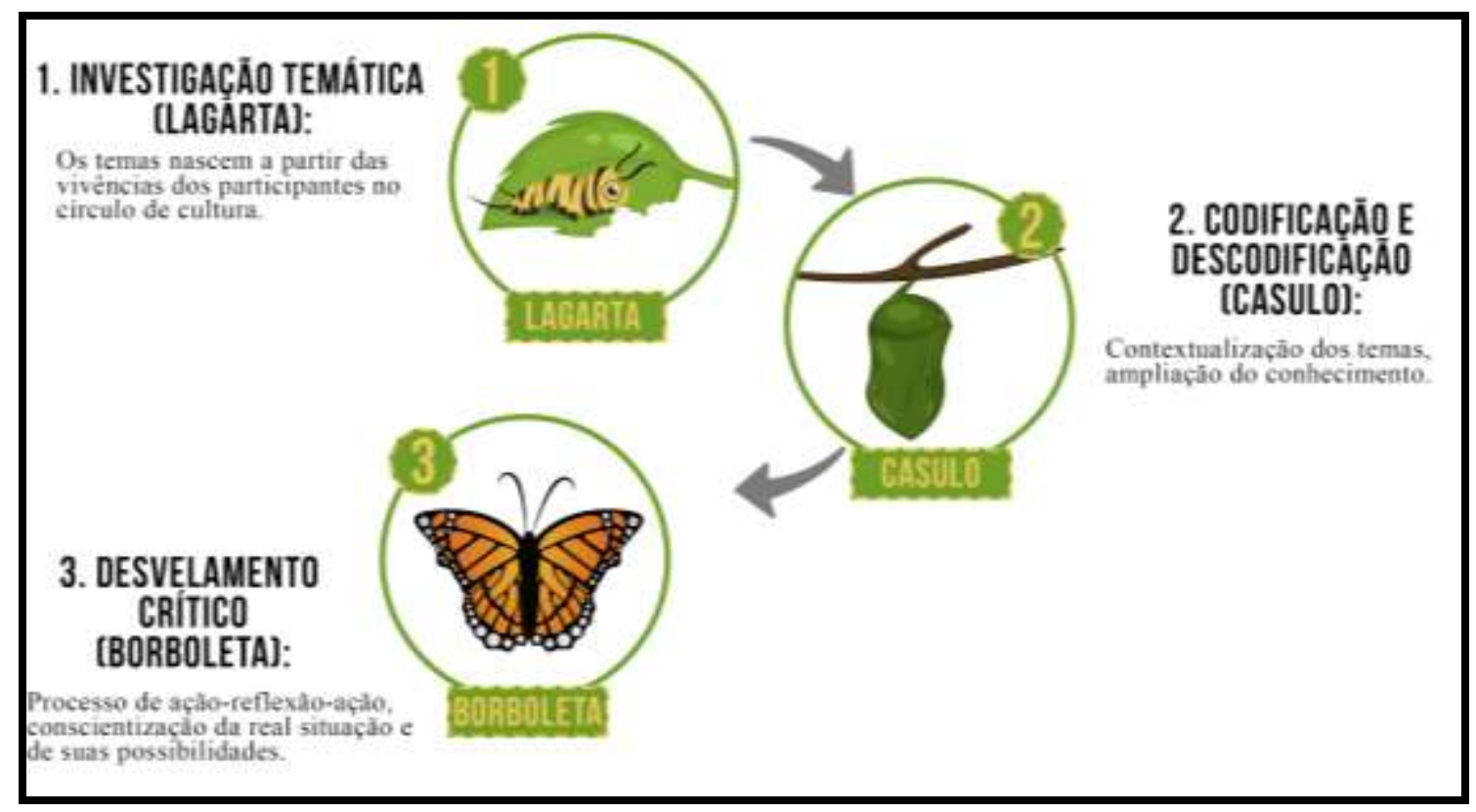

Fonte: Autores, a partir de freepik.com.

O Círculo de Cultura Virtual (CCV) foi desenvolvido no mês de julho de 2020, com duração de aproximadamente duas horas, sendo mediado por uma docente, cirurgiã-dentista, doutora, com experiência neste tipo de abordagem e que já possuía contato com alguns participantes devido sua atuação no PET-Saúde Interprossionalidade. Para instigar o diálogo, a mediadora projetou na tela do dispositivo eletrônico a figura de uma borboleta, refletindo sobre o ciclo de vida deste animal, que permanece por um período enclausurado até a sua transformação, tal como a vida dos participantes do estudo que estavam em formação acadêmica (processo de transformação), mas que no momento necessitavam permanecer em distanciamento social (enclausuramento) por imposição da pandemia de COVID-19.

Para a primeira fase do Itinerário de Pesquisa, Investigação Temática, foi lançado o seguinte questionamento: Quais as repercussões da COVID-19 na percepção dos estudantes de graduação da área da saúde? Os estudantes foram orientados a escrever, em um quadro projetado na tela dos seus dispositivos eletrônicos, um termo para representar suas percepções frente a questão disparadora. Em seguida, cada participante apresentou suas reflexões ao grupo. A mediadora convidou os graduandos a observar os termos descritos no quadro. Assim, organizaram e elegeram dois temas geradores para discussão no CCV: 1) Sentimentos e 2) Mudanças.

Com a definição dos dois temas geradores, percorreu-se a segunda etapa, Codificação e Descodificação, em que a mediadora os questionou: Quais sentimentos emergem diante da pandemia de COVID-19? Quais as mudanças ocorreram no enfrentamento à COVID-19? Os estudantes responderam espontaneamente aos questionamentos, enquanto a mediadora registrava seus depoimentos, por meio de palavras-chave, nas asas da borboleta projetada na tela dos seus dispositivos eletrônicos. Inseriu-se de um lado as reflexões referentes ao primeiro tema gerador e do outro lado, descreveu-se sobre o segundo tema, que ficou representado conforme a Figura 2. 
Figura 2 - Representação da codificação e descodificação dos temas geradores. Chapecó, SC, Brasil, 2020.

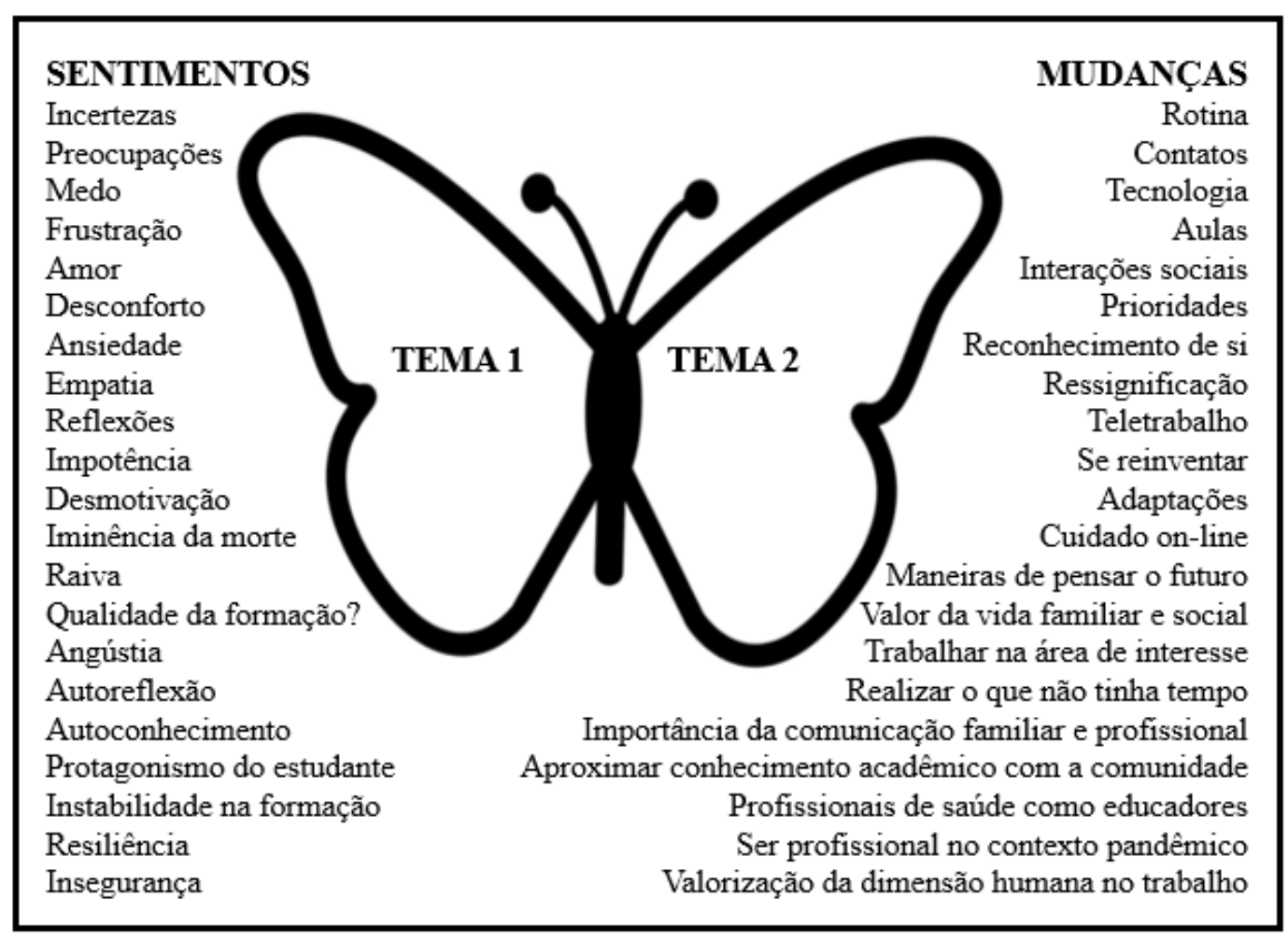

Fonte: Extraído dos depoimentos dos participantes durante o CCV.

Após ampla discussão, em que todos puderam se expressar, passou-se para a terceira etapa do Desvelamento Crítico, em que todas as anotações realizadas foram resgatadas. Assim, as reflexões sintetizadas foram lidas, conjuntamente, a fim de validar esse processo de ação-reflexão-ação (Heidemann et al., 2017). Somado a isso, foi oportunizado o acréscimo de novas reflexões, caso assim desejassem os estudantes, instigando-os a compartilhar suas impressões sobre o significado da participação no CCV durante o momento pandêmico.

Os diálogos do CCV foram gravados, transcritos e organizados em pastas digitais, de acordo com os dois temas geradores. A análise dos dados se realizou de maneira simultânea ao desenvolvimento do CCV, conforme se prevê no Itinerário de Pesquisa de Freire (Heidemann et al., 2017).

O estudo seguiu os preceitos éticos da Resolução 466 de 2012, sendo iniciado após a aprovação por um Comitê de Ética em Pesquisa com seres humanos. O Termo de Consentimento Livre e Esclarecido foi enviado por e-mail para os estudantes após o convite para participar do estudo. Eles assinaram e devolveram para os pesquisadores, antes da realização da atividade. $\mathrm{O}$ anonimato dos participantes do estudo foi preservado a partir da utilização de nomes de borboletas.

\section{Resultados}

Os 15 participantes do estudo foram estudantes da área da saúde, representantes dos seguintes cursos: três da Psicologia, cinco da Medicina, seis da Enfermagem e um da Educação Física. Todos estavam sem aulas presenciais devido a situação de pandemia, sendo quatro do sexo masculino e onze do sexo feminino, com idades entre 19 e 23 anos. No momento do CCV, os estudantes encontravam-se em diferentes localidades da Região Sul do Brasil.

Durante a discussão do primeiro tema gerador, em que se abordou os sentimentos no enfrentamento da pandemia de COVID-19, os estudantes destacaram as incertezas, a iminência da morte, a insegurança, a angústia, o desânimo, a frustração, 
o desconforto, a ansiedade, a raiva, as preocupações, o medo, a impotência e as dúvidas com relação à qualidade da sua formação:

O ano de 2020 era para ser especial, só que daí veio a COVID-19 e todos os planos da minha vida tive que jogar fora e agora estou cheia de incertezas: vou conseguir me formar? Vou conseguir sentar ao lado da minha família e amigos sem usar máscaras? (Apollo);

Essa pandemia veio pra eu perceber a iminência da morte e antes, a gente estava engrenado na rotina, sem muita consciência das coisas [...] (Azul);

Eu achei que essa pandemia seria breve, mas agora começou a vir a insegurança, a pensar que estou perdendo tempo, me sinto angustiada e desanimada (Flambeau);

Eu gosto de seguir rotinas e agora, fica frustrante porque não consigo estabelecer uma rotina, tendo que readaptarse ao novo momento, que traz desconforto e ansiedade. Eu acho que a partir de agora, a gente vai ter que aprender a viver de maneira diferente (Rabo de Andorinha);

Eu sinto muita raiva [...] raiva das pessoas que não fazem a parte deles e não se cuidam, não pensam nos outros. Tenho raiva também de tudo isso que está acontecendo (Coruja);

Eu estou preocupada com muitas coisas, com a qualidade da minha formação [...] e me sinto impotente diante de tudo isso (Almirante Vermelho).

Os estudantes afirmaram que uma das repercussões da COVID-19 foi o abalo da saúde mental, o que os desmotivou para realizar as atividades:

A minha saúde mental foi lá pra baixo, não está sendo fácil pra muita gente toda essa situação (Apollo);

A gente vive um paradoxo [...] antes eu tinha muita coisa pra fazer e não tinha tempo. Agora eu tenho tempo, mas me sinto desmotivada (Morpho);

Com isso tudo acontecendo, fez com que minha saúde mental ficasse bem ruim (Folha).

Diante de tais sentimentos, os estudantes também desvelaram a oportunidade de desenvolver a autorreflexão, o autoconhecimento, a empatia, o amor, a resiliência e o seu protagonismo:

Agora, é um momento de retrospecção de olhar pra dentro de nós e fazer nossa vida valer a pena (Pavão Diurno);

Mas esse momento serviu para eu me aproximar um pouco mais de mim mesma e refletir [...] e também pra desenvolver mais a empatia (Oitenta e oito); 
O amor é o sentimento chave desse momento porque é pelo amor à vida, é por amor ao próximo que a gente tem conduzido e tentado manter a restrição social (Greta Oro);

A gente tem que desenvolver a resiliência e buscar superar essas situações difíceis [...] e ser protagonista nas ações pra buscar melhorar nossa vida (Angel).

Nas discussões do segundo tema gerador, os participantes apontaram as mudanças que ocorreram em suas vidas a partir da pandemia de COVID-19, como as aulas em formato remoto, a maneira de agir e conviver (interação social) com amigos e familiares, bem como suas rotinas e contatos, a presença do teletrabalho e as maneiras de refletir sobre o futuro:

Assim como a borboleta passa pela metamorfose, a gente também se transforma todos os dias e essa pandemia trouxe muita transformação (Esmeralda);

Tudo teve que ser modificado: a maneira das aulas, o tema da minha pesquisa, a maneira de a gente agir, as maneiras de conviver em sociedade (Folha);

Está difícil manter a rotina de acordar cedo e estudar como era antes. Agora, tudo está diferente e acho que a rotina de todo mundo mudou (Flambeau);

As mudanças no mundo do trabalho, como o home-office e o tele-trabalho, acho que veio pra se perpetuar, porque é vantajoso vender pela internet e não pagar aluguel. Com a pandemia, se descobriu que é possível, em muitas áreas, trabalhar dentro de casa (Angel);

Mudou a maneira de a gente pensar no futuro [...] (Greta Oro).

Na vivência do enfrentamento à COVID-19, os estudantes ressignificaram suas prioridades, se reconheceram, proporcionando reflexões sobre o valor da vida familiar e social:

O que era especial antes, agora não é mais. A gente perdeu muito dinheiro esse ano e de fato, em que temos agregado preço e valor? A pandemia me fez pensar nisso (Oitenta e oito);

Eu tenho mudado minha visão de mundo e ressignificado as coisas, dando uma pausa pra aquela correria, com novas formas de desenvolver atividades e estudar (Pavão Diurno);

Eu nunca imaginei que um dia algo tão pequeno, como um vírus, fosse capaz de nos impedir de abraçar e estar com a nossa família e amigos. Então, acho que daqui pra frente, nada vai ser como antes. Hoje, eu vejo o valor da convivência familiar e social (Azul).

Somado a isso, destacaram que a pandemia possibilitou a disponibilidade de trabalhar na sua área de interesse, bem como a oportunidade de se reinventar, buscar novos afazeres e realizar o que não tinham tempo anteriormente: 
A fase da quarentena serviu para eu rever o que de fato eu gosto porque eu fazia produção em massa na universidade, escrevendo artigos, participando de projetos pesquisa e extensão, mas agora acabei procurando o que de fato eu gostava de fazer e descobri novas oportunidades, me dando disponibilidade para trabalhar na enfermagem na área que eu gosto e não em fazer o que mandam eu fazer (Zebra);

Com essas mudanças, a gente tem que buscar o novo, dentro do nosso velho, porque mesmo sendo difícil, a gente tem que aproveitar esse tempo para fazer o que não tínhamos tempo antes e reinventar novas coisas pra fazer (Esmeralda).

Além disso, as modificações impostas pela COVID-19 repercutiram em mudanças na formação dos estudantes, que passaram a reconhecer a importância de aproximar o conhecimento acadêmico da comunidade, tornando-se educadores, com valorização da dimensão humana no trabalho, dando-se conta de que serão profissionais recém-formados em um contexto pandêmico:

Na área da saúde, surgiu a oportunidade de atender via online e tem sido muito interessante, uma nova maneira de cuidado (Folha);

Com essas mudanças, com tantas mortes e fake news, fez com que a gente se tornasse profissional, educador, orientando vizinhos e amigos, aproximando o conhecimento acadêmico à população (Greta Oro);

Nós vamos nos formar bem nesse momento pandêmico e é desafiador [...] é preciso valorizar toda essa dimensão e principalmente a questão humana no nosso trabalho. As pessoas têm sentimentos e a gente tem que lembrar da humanização no atendimento (Morpho);

A gente não tem que trabalhar com o corpo, mas trabalhar com o humano. As pessoas estão sofrendo e isso preciso ser visto daqui pra frente (Angel).

Os estudantes agradeceram pela oportunidade de participar do CCV, em que puderam dialogar e refletir sobre seus sentimentos, o que gerou motivação e transformação, evidenciando a importância de promover espaços semelhantes com vistas a proporcionar a troca de experiências e a aprendizagem mútua, em busca de uma melhor qualidade de vida no enfrentamento da pandemia COVID-19:

Valeu a pena ter acordado cedo neste dia frio porque tive a oportunidade de abrir meus sentimentos com vocês, refletir, repensar e aprender (Zebra);

Foi um privilégio nós termos participado porque pudemos conversar, expor nossas angústias e mais pessoas tinham que ter essa oportunidade também (Folha);

Foi muito bom parar pra refletir com vocês e perceber que tem mais pessoas como eu, com os mesmos problemas, dúvidas e sentimentos (Azul). 


\section{Discussão}

Os estudantes integram uma das populações que mais apresentaram sintomas negativos relacionados à COVID-19 e maior vulnerabilidade ao estresse, ansiedade e medo persistentes (Qiu et al., 2020). Os universitários tiveram suas rotinas modificadas, com a suspensão das aulas, logo no início da pandemia. Isso pode ter estimulado maiores dificuldades de adequação ao distanciamento social e a manifestação de impactos psicológicos negativos neste enfrentamento (Maia \& Dias, 2020).

O distanciamento social, adotado como medida para impedir o contágio, alude a conservação de uma distância espacial, de aproximadamente dois metros, entre as pessoas (CDCP, 2020). Desta forma, não deve haver agrupamentos, mas tal medida pode afetar a saúde mental dos envolvidos. Entre os sentimentos estressores desencadeados com o distanciamento social cita-se: a ausência de contato físico com amigos e familiares, incertezas, frustração (Brooks et al., 2020), medo (Lima et al., 2020), depressão (Pancani et al., 2020), insônia, ansiedade, raiva, ruminação, diminuição da concentração, mau humor e perda de energia (Park \& Park, 2020).

Os depoimentos, ao serem associados na construção do corpus de sentidos que fazem parte desta investigação, apresentaram que no início da pandemia os estudantes manifestaram um conjunto de sentimentos. Dentre eles considera-se a incerteza o principal, pois ao ser vivenciada desencadeou os demais sentimentos negativos. Esses sentimentos causam importantes desconfortos entre os estudantes, algo que fomentou as incertezas do cotidiano.

$\mathrm{O}$ sentimento de incerteza é facilmente identificado entre pessoas que vivenciam situações de adoecimento, pois corresponde a inabilidade de lidar com eventos que alteram o fluxo da vida (Zhang et al., 2020). A falta de conhecimento acerca do fenômeno vivenciado pode potencializar o sentimento de incerteza e, por conseguinte, desencadear problemas psicológicos como ansiedade e depressão (Katsumotoet al., 2019).

Assim, a incerteza é a má adaptação de um indivíduo diante de uma situação controversa, ou seja, não esperada (CDCP, 2020). Logo, entende-se que a pandemia de COVID-19 desencadeou incertezas nos estudantes pela falta de conhecimento sobre o comportamento da doença, sobre o fim das medidas de distanciamento social e por não saberem como continuar suas vidas neste contexto.

Apesar das percepções restritivas que o mundo social proporcionou aos estudantes durante a pandemia, houve um ou mais momentos de ruptura do modo como estavam vivenciando esta realidade. A partir de então, passaram a criar estratégias para lidar com as limitações impostas pela disseminação do COVID-19, abrindo espaço para sentimentos positivos como a empatia, o amor, a resiliência, o autoconhecimento que culminaram num processo de autorreflexão.

Autorrefletir é repensar atitudes e práticas performadas cotidianamente. Para que a autorreflexão ocorra, é necessário que o indivíduo reconheça algo que lhe incomode e busque por medidas que visem mudanças (Neto \& Peixoto, 2018). Este é um conceito frequentemente empregado nas ciências da educação e se refere a ação de repensar a prática docente que, ao ser generalizada a outros grupos, entende que os indivíduos são capazes de promover mudanças em suas realidades (Andrade \& Martins, 2018). Logo, podem mudar a perspectiva que possuem sobre a pandemia, como no caso dos estudantes, que buscaram refletir sobre as potencialidades do momento vivido, na tentativa de sobrepor o que consideravam ser incômodo.

A autorreflexão estimulou os estudantes a buscarem por estratégias para o enfrentamento do momento presente, na tentativa de promover mudanças significativas na forma como se relacionam socialmente. Os sentimentos vivenciados, as estratégias de enfrentamento produzidas e a percepção de um futuro diferente propiciaram rever suas prioridades na vida. Nesse período, o estar com a família e amigos obteve outra valoração, sobretudo por não poder tocá-los de modo afetuoso, algo que anteriormente era negligenciado, hoje é necessário. 
Entre as consequências da pandemia de COVID-19 diante da necessidade de distanciamento social, estudo aponta que a coexistência permaneceu a mesma ou melhorou por terem e receberem mais tempo e apoio das pessoas com quem convivem: aumentaram a frequência e a qualidade afetiva de seus relacionamentos com pais, filhos, amigos e vizinhos (Lasa et al., 2020).

$\mathrm{Na}$ vivência da situação pandêmica, várias pessoas consideraram positivo poder contar com o tempo que lhes permitiu desfrutar e valorizar melhor os laços familiares e aprenderam a aproveitar as vantagens de ficar em casa: maior disponibilidade de tempo e capacidade de repensar valores vitais, esperança de que a crise e o confinamento possam servir de mudança social, devido à mudança de valores que podem ser derivados da experiência e que levarão a um melhor relacionamento entre os vizinhos e ao desfrute das atividades diárias (Lasa et al., 2020).

As políticas de distanciamento social ocasionaram transformações e direcionaram a diminuição da obrigatoriedade de sincronicidade nas relações sociais. Acredita-se que por segurança, comodidade ou inércia, as atividades a partir de então, ficaram potencialmente restritas ao espaço doméstico e digitalmente difundidas, pois as mudanças desencadeadas pela COVID-19 nos estilos de vida, ainda possuem grande potencial de serem duradouras (Mattedi et al., 2020).

$\mathrm{Na}$ Alemanha e na China, pesquisadores destacam que o medo da infecção é uma constante entre a população, sendo os profissionais da enfermagem o grupo populacional que apresentou com mais frequência o sofrimento mental decorrente da pandemia (Shi et al., 2020). Novamente, os autores frisaram a necessidade de apoio para que as pessoas criem estratégias de enfrentamento. É válido ressaltar que estudantes da área da saúde possuem mais informações acerca do SARS-COV-2 e do COVID-19 do que a população leiga o que, consequentemente, leva a uma maior compreensão relacionada à gravidade da situação e como elas podem ocorrer em si e em seus familiares. Portanto, é importante oferecer suporte a este grupo, com fins de promoção da saúde mental.

O distanciamento exacerbou as preocupações consigo e com os outros, o que aumentou a reflexão do protagonismo das pessoas e seu papel social (Brooks et al., 2020). Ao olharem para o seu processo formativo, os estudantes perceberam que a pandemia thes proporcionou algo positivo: poder colocar em prática o conhecimento adquirido na universidade. Neste momento, os estudantes se reconheceram como educadores sociais, pois disseminaram informações corretas sobre a COVID19 e desmistificaram informações errôneas propagadas na sociedade. Tal ação ratificou nos estudantes o desejo de continuarem na área da saúde pois, segundo eles, essa é uma das competências que desejam manter na vida profissional, além do fato deste cenário ter empregado mais valor social aos profissionais da saúde.

O distanciamento social imposto pela pandemia desencadeou diferentes formas de pensar e agir, mobilizando os indivíduos, as instituições de ensino e as instâncias governamentais para reorganizar as ações propostas no ensino superior. Desta forma, as universidades direcionaram suas atividades para serem realizadas em home office, com a preocupação de assegurar a manutenção da qualidade da formação profissional em saúde de modo equitativo (Costa et al., 2020).

O CCV se conformou como um ambiente terapêutico para os estudantes compartilharem suas vivências, o que foi entendido como positivo pelo grupo. A participação em atividades de grupo reflete uma importante rede de apoio social. Os encontros virtuais pode ser uma estratégia significativa para a saúde mental no período de isolamento por oportunizar que as pessoas se aproximem por meio da janela virtual. As pessoas que participam destas atividades são gratas pela oportunidade de estarem juntas, serem acolhidas de forma sensível e cuidadosa. Os encontros virtuais superam as barreiras geográficas e psíquicas e ativam a noção de pertencimento, de identificação e de coletividade neste período de pandemia (Rodrigues et al., 2020).

A principal limitação desse estudo esteve relacionada ao tempo disponível para o debate no CCV, pois mesmo após duas horas de intenso diálogo, seria interessante haver maior período para aprofundamento das temáticas. Além disso, acreditase que o contato físico seria um fator interessante, visto que os estudantes se apresentavam sensíveis, mas com a realização do CVV tornou-se impossível o toque. No entanto, ao reconhecer tais limitações, que é peculiar a abordagem utilizada durante a 
necessidade de distanciamento social, incentiva-se a sua replicação a outros púbicos, que também precisam de espaços para refletir sobre as repercussões da COVID-19.

\section{Considerações Finais}

A pandemia da COVID-19 provocou importantes mudanças no cotidiano dos participantes do estudo. A partir do desenvolvimento do CCV foi possível se aproximar dos sentimentos que permeiam o imaginário dos estudantes de cursos de graduação em saúde e ampliar a compreensão relacionada às ressignificações e modos de viver encontrados por eles.

Os participantes descreveram e refletiram sobre os sentimentos que surgiram durante o distanciamento social imposto pela pandemia, como: incertezas, iminência da morte, insegurança, angústia, desânimo, frustração, desconforto, ansiedade, raiva, preocupações, dentre outros. Ao mesmo tempo, encontraram novas estratégias de enfrentamento que permitiram ressignificar esses sentimentos negativos e experimentar novos sentimentos como empatia, amor e resiliência.

Os estudantes não haviam encontrado, até então, espaços para expressar seus sentimentos, enfrentamentos e aprendizados legados da pandemia. Portanto, neste estudo, o CCV se conformou como "um espaço" terapêutico, além de cumprir os propósitos de produção e análise de dados.

Além disso, o CCV proporcionou o encontro dos estudantes que se encontravam em diferentes locais do Brasil, sem as barreiras de custos e deslocamentos geográficos necessários para atividades na modalidade presencial, de maneira humanizada, integral e acolhedora. Destaque-se a relevância e os impactos positivos que esta estratégia pode alcançar com diferentes públicos, de diferentes localidades, em tempos de pandemia, onde o distanciamento social configura-se como ferramenta indispensável para minimizar a disseminação da COVID-19. A estratégia de CCV foi desvelada como relevante ferramenta de pesquisa e principalmente de promoção da saúde para ser implementada por profissionais da área da saúde.

As percepções apresentadas e discutidas oferecem subsídios que irão auxiliar na organização da vida estudantil, especialmente na área da saúde, no contexto pós-pandêmico. Somado a isso, evidencia-se a premência de voltar os olhos para este público para que os profissionais da saúde e universidades possam desenvolver ações em prol do bem-estar dos estudantes no enfrentamento das repercussões da COVID-19 em suas vidas.

Recomendamos a realização de outros estudos com estudantes universitários, especialmente na área da saúde, no sentido de ampliar o conhecimento relacionado aos sentimentos e as mudanças geradas pelo período pandêmico.

\section{Referências}

Andrade, A. I., \& Martins, F. (2018). Educação global e diversidade linguística na formação inicial de educadores e professores: da intervenção à (auto)reflexão. Indagatio Didactica. 10(1):47-62.

Aristovnik, A., Keržič, D., Ravšelj, D., Tomaževič, N., \& Umek, L (2020) Impacts of the COVID-19 Pandemic on Life of Higher Education Students: A Global Perspective. Sustainability. 12(20):8438. https://doi.org/10.3390/su12208438.

Brooks, S. K., Webster, R. K., Smith, L. E., Woodland, L., Wessely, S., Greenberg, N., \& Rubin, G. J. (2020). The psychological impact of quarantine and how to reduce it: rapid review of the evidence. The Lancet. 395(102227):912-920.

Cao, W., et al (2020). The psychological impact of the COVID-19 epidemic on college students in China. Psychiatry Res. 287:1-5.

Centers for Disease Control and Prevention. Social distancing, quarantine, and isolation: keep your distance to slow the spread. Atlanta http://www.cdc.gov/coronavirus/2019-ncov/prevent-getting-sick/social-distancing.htm

Costa, R., et al (2020). Ensino de enfermagem em tempos de COVID-19: como se reinventar nesse contexto? Texto contexto - enferm. 29 : e20200202.

Heidemann, I. T. S. B., et al. (2017). Reflexões sobre o itinerário de pesquisa de Paulo Freire: contribuições para a saúde. Texto Contexto Enferm. 26(4):e0680017.

Katsumoto, S., et al (2019). Uncertainty in young adult survivors of childhood and adolescent cancer with lower-extremity bone tumors in Japan. $J$ Adolesc Young Adult Oncol. 8(3):291-6. 
Research, Society and Development, v. 10, n. 10, e160101018687, 2021

(CC BY 4.0) | ISSN 2525-3409 | DOI: http://dx.doi.org/10.33448/rsd-v10i10.18687

Lasa, N. B., et al (2020). Las consecuencias psicológicas de la COVID-19 y el confinamiento. Servicio de Publicaciones de la Universidad del País Vasco Euskal Herriko Unibertsitateko Argitalpen Zerbitzua. https://www.ciencia.gob.es/stfls/MICINN/Universidades/Ficheros/C onsecuencias_psicologicasCOVID19.pdf

Lima, C. K. T., et al. (2020). The emotional impact of coronavirus 2019-Ncov (new Coronavirus Disease). Psychiatry Res. 287:e112915.

Lipsitch, M., Swerdlow, D. L., \& Finelli, L. (2020). Defining the Epidemiology of Covid-19 - Studies Needed. N Engl J Med. 382:1194-6.

Liu, S., et al. (2020) Online mental health services in China during the COVID-19 outbreak. Lancet Psychiatry. 7(4):e17-e18.

Maia, B. R., \& Dias, P. C. (2020). Ansiedade, depressão e estresse em estudantes universitários: o impacto da COVID-19. Estud. psicol. $395: 470-3$.

Marques, G., et al (2021). Impact of COVID-19 on the psychological health of university students in Spain and their attitudes toward Mobile mental health solutions. Int J Med Inform. 147:104369.

Mattedi, M. A., et al(2020). Epidemia e contenção: cenários emergentes do pós-Covid-19. Estud. av. 34(99):283-302.

Meo, S. A., Abukhalaf, D., Alomar, A. A., Sattar, K., \& Klonoff, D. (2020). COVID-19 pandemic: impact of quarantine on medical students' mental wellbeing and learning behaviors. Pak J Med Sci. 36(S4):S43-S48.

Neto, M., \& Peixoto, A (2018). O processo de auto-supervisão, auto-reflexão e auto-observação: um estudo de caso. CIAIQ2018. 1:318-329.

Pancani, L., Marinucci, M., Aureli, N., \& Riva, P (2020). Forced social isolation and mental health: a study on 1006 Italians under COVID-19 quarantine. PsyArXiv. https://doi.org/10.31234/osf.io/uacfj

Park, S., \& Park, Y. C. (2020). Mental health care measures in response to the 2019 novel coronavirus outbreak in Korea. Psychiatry Investig. 17(2):85-6.

Qiu, J., et al (2020). A nationwide survey of psychological distress among Chinese people in the COVID-19 epidemic: implications and policy recommendations. Gen Psychiatr. 33(2):e100213.

Rodrigues, R., Coutinho, E., Barea, J., \& Aguiar, A. (2020). Teatro de reprise telepresencial em tempos de COVID 19. Rev. bras. Psicodrama. 28(2):142-153. https://doi.org/10.15329/2318-0498.20836 .

Shi, L., et al (2020). Prevalence of and risk factors associated with mental health symptoms among the general population in China during the Coronavirus disease 2019 pandemic. JAMA Netw Open. 3(7):e2014053.

Silva, E. L. M., et al. (2021). O uso de Lopinavir e Ritonavir como alternativa terapêtica para a COVID-19. Research, Society and Development. 10(7):1-12.

Singhal, T. (2020). A review of coronavirus disease-2019 (COVID-19). Indian J Pediatr. 87(4):281-6.

Varner, S., et al (2019). Illness uncertainty, partner support, and quality of life: A dyadic longitudinal investigation of couples facing prostate cancer. Psychooncology. 28(11):2188-2194.

Wang, C., Horby, P. W., Hayden, F. G., \& Gao, G. F. (2020). A novel coronavirus outbreak of global health concern. Lancet [Internet]. 395:470-3.

Zhang, Y., Kwekkeboom, K., Kim, K. S., Loring, S., \& Wieben, A. M. Systematic review and meta-analysis of psychosocial uncertainty management interventions. Nurs Res. 69(1):3-12. https://doi.org/10.1097/NNR.0000000000000368 